\title{
The Cultural Dependence of the Ethical Sensitivity Scale Questionnaire: The Case of Iranian Kurdish Teachers
}

\author{
Khalil Gholami $^{1,2}$ and Kirsi Tirri ${ }^{2}$ \\ ${ }^{1}$ Department of Education, University of Kurdistan, P.O. Box 416, 66177-15175, Sanandaj, Iran \\ ${ }^{2}$ Department of Teacher Education, University of Helsinki, P.O. Box 9 (Siltavuorenpenger 5), 00014 Helsinki, Finland
}

Correspondence should be addressed to Khalil Gholami, khalil.gholami@helsinki.fi

Received 21 February 2012; Revised 2 May 2012; Accepted 13 May 2012

Academic Editor: Terence J. Lovat

Copyright ( $\odot 2012$ K. Gholami and K. Tirri. This is an open access article distributed under the Creative Commons Attribution License, which permits unrestricted use, distribution, and reproduction in any medium, provided the original work is properly cited.

A good theory-based tool for measuring ethical sensitivity, which is usable in different contexts, is scarce. In this study, we examined the Ethical Sensitivity Scale Questionnaire (ESSQ) in line with its seven-dimension structure. The scale was presented to a sample of 556 Iranian Kurdish teachers in primary, middle, and high schools. A confirmatory factor analysis was conducted to scrutinize the original factor structure of the ESSQ. The results confirmed that the ESSQ supports a reasonable model fit to study the seven dimensions of ethical sensitivity as it was developed in the original study. However, some modifications were conducted to free high error covariance between four pairs of items in the scale. This modification increased the fit indices and thus resulted in a good model fit. In addition to examining the satiability of the ESSQ, a further analysis showed that the level of ethical sensitivity in the targeted sample was high.

\section{Introduction}

Ethical sensitivity is a fundamental element of human moral conduct. Ethical sensitivity was coined for the first time by Rest [1] and it is the first important component of his 4component moral action theory. In a general sense, ethical sensitivity is the identification of salient aspects of a situation that involves the "good" and the "bad" of others. Weaver et al. [2] define ethical sensitivity as "the capacity to decide with intelligence and compassion, given uncertainty in a care situation. .. with additional ability to anticipate consequences and courage to act." According to Tirri and Nokelainen [3] "to respond to a situation in a moral way, a person must be able to perceive and interpret events in a way that leads to ethical action". The central feature of ethical sensitivity is the ability to read a caring situation in order to respond with an ethical action, that is, a human conduct whereby the others' benefits and loses are taken into consideration. As such, the primary assumption in research on ethical sensitivity is that something one might do or is doing can affect the welfare of someone else. Discerning that a situation requires a moral response is the first step in the process of moral action [4].
Recently there has been a significant conceptual insight into the topic in different studies $[2,5]$. As an empirical concept, Weaver et al. [2] found that ethical sensitivity has five basic aspects in various professions and domains. "Attributes" which refers to basic characteristics of the concept includes moral perception, affectivity, and dividing loyalties. "Moral perception involves awakening and particularizing, which allows professional to perceive client situational needs.... Affectivity is a relational component based on professional putting oneself in the place of clients and identifying comparable reactions... and dividing loyalties refers to strategies of interpretation, justification, and flexibility to deal with authenticate and contradict moral perception". Definition is the second aspect of ethical sensitivity, where the research shows there has been a multiplediscipline description and definition of ethical sensitivity but "decision-making within the uncertainty of professional practice" has been considered as a central feature to define ethical sensitivity. Preconditions is another aspect of ethical sensitivity, which refers to client suffering and vulnerability and professionals' perspectives of uncertainty, receptivity, 
responsiveness, and courage to deal with this suffering. As another aspect of ethical sensitivity, "Boundaries" passes on what is and is not, in this concept, based on previous aspects of ethical sensitivity. Moreover, ethical sensitivity has "outcomes" such as "integrity, comfort, well-being, personal growth, professional self-transcendence, and practical wisdom" for clients [2].

These conceptual insights into the topic encouraged researchers in various domains to conduct empirical studies on ethical sensitivity. This trend has shifted researchers' attention from Kohlberg's moral judgment to ethical sensitivity. Jordan states that one reason for the recent increase in attention to moral sensitivity may be that there are now several methods for measuring this construct, for example, the Dental Ethical Sensitivity Test, ethical sensitivity in television viewing, the Racial Ethical Sensitivity Test, moral sensitivity in counseling supervision, moral sensitivity in social work, ethical sensitivity in accounting, and several other measures [6]. Using these measures, a significant body of research has been conducted to examine ethical sensitivity in various professions such as nursing and medicine [7-9], news [10], and business and accounting [11]. These studies have also addressed different issues such as gender, cultural, nationality, and racial differences in regarding to ethical sensitivity.

As can be seen, most of these measures are domain specific and may not be applied in a different context. Drawing on Narvaez and Endicott [12], Tirri and Nokelainen have developed a measure, the Ethical Sensitivity Scale Questionnaire (ESSQ), which is more general and thus can be applied in different professional contexts. Using this measure, this research examined teachers' ethical sensitivity [13].

Numerous studies have showed that teaching is a moral activity by nature. Narvaez [14] believes that "because humans are wired for emotion signaling and social motivation, a caring, supportive teacher more easily foster students' empathy and prosocial behavior as well as motivation to learn.... Children with poor early care will have brains that are less flexible, integrated, and attentive, represented by poor attachment but with patience and supportiveness, these children can be reached." Higgins stated that "talk about teaching is talk about the present and the past and the future of persons.... Teaching is an act of caringcaring for the world and another human being. Teaching requires responding to the student as a worthy human being." [15] According to Hansen, every moment of the classroom life emits moral messages. Thus "If teachers sought to be constantly alert to the moral impact of their work, they might find themselves suddenly walking on eggshells in the classroom, fearful that at any moment a single word or deed might morally injure a student" [16]. In a philosophical term, the moral foundation of teaching can be met with what has been called "teachers' manner". In line with this reflection, empirical evidence shows that along with method, which is used to convey knowledge to the learners, teachers should have good "manner" to convey virtue [17-20].
Narvaez has proposed a popular framework that can help educators gain insight into the moral foundation of teaching and teachers' manner. According to this framework, a moral agent and particularly a teacher should have four basic ethical skills namely ethical sensitivity, ethical judgment, ethical focus, and ethical action in order to develop moral character of students $[14,21]$. Teachers with these ethical skills provide a sustainable pedagogical climate, in which children "foster secure attachment, develop more agreeable personalities, earlier conscience, and more prosociality". In this framework, ethical sensitivity is the "opening door" for conducting moral action because it deals with "concern for others". Most of pedagogical decisions in classroom life involve taking care of students in different ways. Different dimensions of ethical sensitivity are very critical skills with which teachers can regulate the emotional, sociological, and pedagogical aspects of their practice. "Reading and expressions feeling" and "caring by connecting to others" help teachers provide an effective emotional relationship with students. With these two skills, teachers can read the existing emotional conditions of students and then care about them with appropriate actions. In addition, "Taking the perspective others," "working with interpersonal and group differences", and "Preventing social bias" are necessary skills to take social aspects of the students into consideration in different ways. These skills can be effective characters for teachers in a multicultural teaching context where students have different gender, ethnic, religious, and cultural backgrounds. "Generating interpretation and options" and "Identifying the consequences of action" are other two dimensions of ethical sensitivity that can improve the pedagogical atmosphere of the teaching context in two ways. "Generating interpretation and options" helps teachers be flexible in dealing with students when they try to have various pedagogical actions to deal with students with different interests and capability. "Identifying the consequences of actions" can be an effective basis for reflective teaching when teachers try to be sensitive to the outcomes of their actions in very critical situations that involve ethical considerations. Figure 1 illustrates how dimensions of ethical sensitivity are connected to teaching as a moral activity.

According to Figure 1, teaching as a moral practice has three important bases, including pedagogical, emotional, and social aspects. Different dimensions of the ethical sensitivity are linked to three bases of teaching as moral practice. If teachers fail to perceive and recognize the moral issues of their work regarding the students, how then can they conduct a moral action? Higgins argued that teaching will turn to be a "care-less activity" if teachers fail to perceive the ethical loading of their pedagogical decisions [15]. Empirical research has shown that ethical sensitivity, especially the skill to read and express emotions, is an important skill for teachers in establishing caring relationships with their students and their families, particularly in schools that have an increasing cultural diversity amongst students [22]. Even though teaching is considered to be a moral action, there seems to be a paucity of empirical research on its first component, that is, ethical sensitivity, particularly in a crosscultural and international context. 


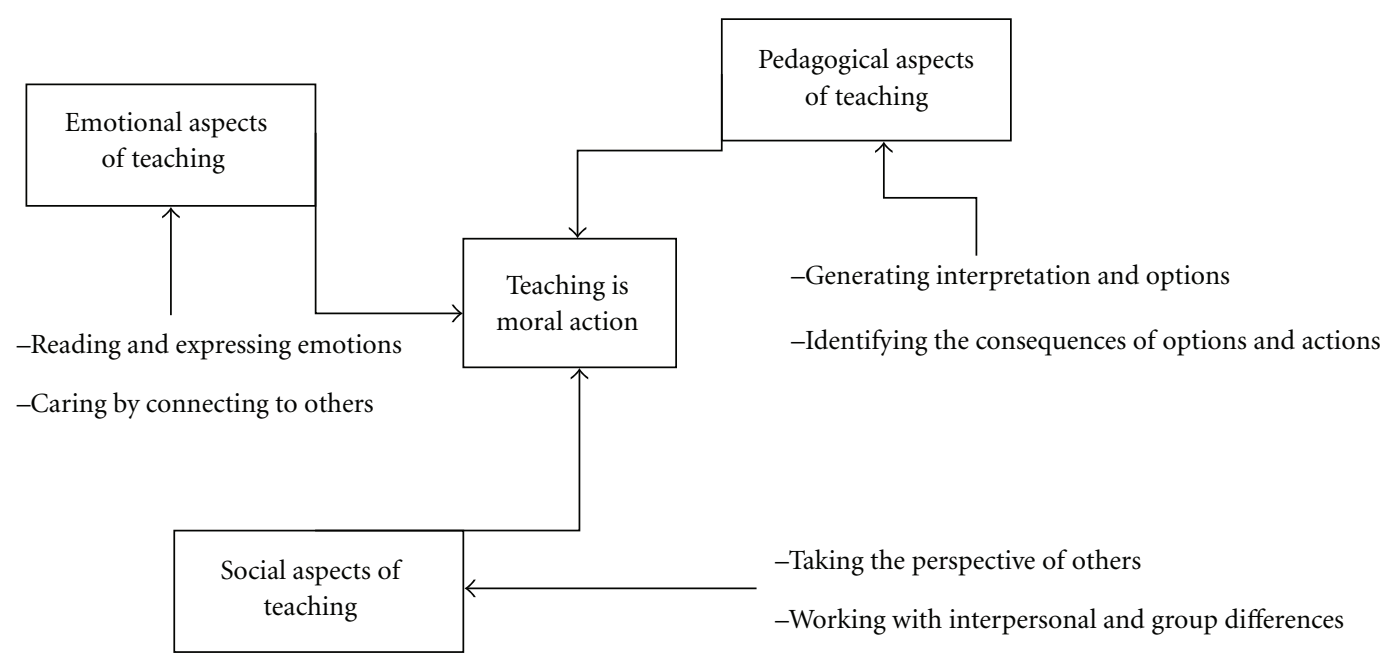

Figure 1: Dimensions of ethical sensitivity and link to teaching.

\section{Teaching and Teacher Education in Iran}

Basic education is compulsory for 12 years in Iran and it is highly centralized and thus governed by the Ministry of Education. It has three different levels of schooling, primary, middle, and high school. Primary school (Dabestan) starts at the age of 7 and lasts for 5 years. Middle school, also known as the orientation cycle (Rahnamayi), goes from the sixth to the eighth grade. High school (Dabirestan) is divided between theoretical (science, mathematics, and humanities) and vocational/technical sections, each program having its own specialties; in the theoretical section, the students have one year studying as a preuniversity course [23]. In line with its educational system, teacher education in Iran is also centralized in terms of its structure and curriculum. In general, particular teacher training centers and universities are responsible for preparing teachers for K-12 education. For primary and middle schools, teachers must generally have a postdiploma (associate degree, i.e., two years further education after graduating from high school); high school teachers must have a bachelor's degree in various subject matters [24]. Primary teachers mainly receive pedagogical education to deal with basic subjects such as science, mathematics, reading, writing, religion, and Persian literature. In order to teach in middle and high schools, teachers, however, must complete both pedagogical and subject-specific education in the different subject matters they intend to teach.

Moral competencies are also highlighted in Iranian teacher education. For all three levels of schooling, teachers must complete a few courses regarding the morality, specifically the moral principles of Islam [25]. In addition, one of the main necessary requirements needed to become a teacher is to have moral and ideological competency [24]. In other words, teachers must show their faith in Islam and Islamic values. This means that teachers' moral competencies should be based on Islamic values and principles. This institutional tendency to integrate Islamic ideology into education and teacher education was the consequence of the so-called Islamic revolution in Iran, which occurred in 1979. According to Cheng and Beigi, "this revolution brought a new era in Iran in which the new Islamic republic began to Islamize many sectors which had secular foundations prior to revolution" [23]. The most striking feature of postrevolution schools is the moral education teacher (Morabbiye tarbitati). This teacher does not teach particular subjects but is responsible for teaching Islamic moral values at various religious events in schools [26]. The primary qualification of this teacher is his/her knowledge of, and faith in, Islam. Other teachers are not allowed to discuss their own values and principles with students, except those regarding to Islamic moral values.

\section{Specific Research Questions}

Considering the context of Iran's teacher education, this paper examines the ethical sensitivity of Kurdish teachers in Iranian's context. Previous scholarship shows that ethics in teaching includes many culture-specific issues, for example the religious worldviews of teachers and students. In Iran's context teaching is influenced by Islamic worldview, which might have implications also for teachers' professional morality including their ethical sensitivity. In the Americanbased theory behind our instrument used [12], the Ethical Sensitivity Scale Questionnaire (ESSQ), ethical sensitivity is operationalized to include seven dimensions with concrete competencies in each dimension. The concrete skills for ethical sensitivity in the context of classroom teaching are discussed in Narvaez [27]. The earlier empirical testing with the ESSQ includes Finnish students and teachers [13, 28]. Finnish context is very American-like European culture with an influence of Christian worldview and Protestant ethics among teachers [29]. However, the instrument has been developed to be used in multicultural contexts and our goal is to test the culture-dependent aspects of the instrument with this specific population of Kurdish teachers whose worldviews differ very much from the Western teachers we 
TABLE 1: Sample description.

\begin{tabular}{|c|c|c|c|c|}
\hline & $\begin{array}{l}\text { Primary teachers } \\
\quad(N=125)\end{array}$ & $\begin{array}{l}\text { Middle school teachers } \\
\qquad(N=221)\end{array}$ & $\begin{array}{l}\text { High school teachers } \\
\qquad(N=204)\end{array}$ & Total $(N=556)$ \\
\hline \multicolumn{5}{|l|}{ Gender N (\%) } \\
\hline Female & $40(32.0)$ & $96(43.4)$ & $88(43.1)$ & $224(40.3)$ \\
\hline Male & $85(68.0)$ & $125(56.6)$ & $116(56.9)$ & $332(59.7)$ \\
\hline \multicolumn{5}{|l|}{ Age } \\
\hline Mean & 35.65 & 34.64 & 35.27 & 35.08 \\
\hline$(\operatorname{Min}-\max )$ & $(21-50)$ & $(20-52)$ & $(20-50)$ & $(20-52)$ \\
\hline $\mathrm{SD}$ & 6.55 & 6.92 & 5.58 & 6.35 \\
\hline \multicolumn{5}{|l|}{ Experience } \\
\hline Mean & 14.45 & 13.24 & 13.61 & 13.63 \\
\hline$($ Min-max $)$ & $(1-23)$ & $(1-28)$ & $(1-27)$ & $(1-28)$ \\
\hline SD & 6.68 & 7.15 & 6.02 & 6.63 \\
\hline
\end{tabular}

have studied before. This empirical investigation will give us more information on the validity of the Ethical Sensitivity Scale Questionnaire (ESSQ). In line with this, the paper addresses two specific research questions.

(1) To what extent can the original constructs of the (ESSQ) be identified among Iranian teachers?

(2) What is the nature and level of ethical sensitivity of Iranian Kurdish teachers?

\section{Methods}

4.1. Sampling Frame. Data was collected from teachers who taught in three levels of K-12 Education in Kurdistan. Kurdistan is one of the 31 provinces in Iran and has about one and half million inhabitants, the majority of which has a Kurdish ethnic background. It has 8 major cities each with a population of over 100,000 inhabitants. The center of the province is Sanandaj with about 400,000 inhabitants. The total number of students and teachers in Kurdistan was 58,979 and 3,274 respectively in 2011. Using nonprobability sampling, data was collected from 556 teachers in the province of Kurdistan. The teachers were asked to complete a paper-and-pencil version of the Ethical Sensitivity Scale Questionnaire (ESSQ). Questionnaires were distributed among schools and delivered to the teachers by school principals. Table 1 illustrates the descriptive statistics of the sample.

4.2. Ethical Sensitivity Scale Questionnaire. Drawing from Narvaez and Endicott [12] the ESSQ measures seven dimensions of ethical sensitivity: reading and expressing emotions, taking the perspectives of others, caring by connecting with others, working with interpersonal and group differences, preventing social bias; generating interpretations and options, and identifying the consequences of actions and options. The measure consists of 28 items; each dimension is measured with 4 items. In the initial investigation on the psychometric properties of the measure, Tirri and Nokelainen found that, due to small sample size, there was a "quite low" level of common variance between items when inter-item correlation was examined [3]. However, the direction of all 378 possible correlation combinations but one (i.e., item es1_4 with es7_28 had negative correlation; $r=$ 0.01 ) was positive. Such positive correlations between items supports Naravaez' operationalization of ethical sensitivity $[3,12]$. Further, reliability analysis of the dimensions showed good results: "Caring by connecting to others" and "Working with interpersonal and group differences" had the highest reliabilities ( $\alpha=0.78 ; \alpha=0.75$ ); "Reading and expressing emotions" and "Preventing social bias" showed the lowest rates $(\alpha=0.54 ; \alpha=0.50)[3]$.

\section{Results}

In line with the main research task, a confirmatory factor analysis (CFA) was conducted to examine the stability of the factor structure of the ESSQ, using LISREL 8.72. In other words, CFA was carried out to confirm the underlying seven structure dimensions of the ESSQ. In examining the model fit, we supported the model $\chi^{2}$ statistic with both absolute and incremental fit indices [30, 31]. Absolute fit indices examine how well an original model reproduces the sample data under study. For this case, we have reported the root mean square error of approximation (RMSEA) and the standardized root mean square residual (SRMR). Incremental fit indices assess model fit by comparing the target model with a baseline model. According to Hulpia et al., "typically, the null model in which all observed variables uncorrelated is used as a baseline model" [30]. Regarding the incremental fit indices, the four most reported ones, including the comparative fit index (CFI), the goodness offit-index (GFI), the incremental fit index (IFI), and the normed fit index (NFI), are reported in our study.

Conducting a CFA with a seven-factor structure of the ESSQ resulted in reasonable model fit (with $\chi^{2}=1248.57$ $[\mathrm{df}=329 ; P<0.00]$, SRMR $=0.064$, RMSEA $=0.071$ with a $90 \%$ confidence interval of 0.067 and 0.075 , CFI $=$ 0.86 , GFI $=0.93$, IFI $=0.93$, NFI $=0.90)$. Different studies have suggested that for SRMR a value of 0.08 or 
TABLE 2: Factor structure and alpha loadings of the ethical sensitivity scale.

\begin{tabular}{lcc}
\hline Dimension & Items & $\alpha$ \\
\hline Reading and expressing emotions & Es1_1, es1_2, es1_3, es1_4 & 0.46 \\
Caring by connecting to others & Es2_5, es2_6, es2_7, es2_8 & 0.60 \\
Taking the perspectives of others & es3_9, es3_10, es3_11, es3_12 & 0.66 \\
Working with interpersonal and group differences & Es4_13, es4_14, es4_14, es4_16 & 0.64 \\
Preventing social bias & Es5_17, es5_18, es5_19, es5_20 & 0.45 \\
Generating interpretations and options & Es6_21, es6_22, es6_23, es6_24 & 0.69 \\
Identifying the consequences of actions and options & Es7_25, es7_26, es7_27, es7_28 & 0.53 \\
\hline
\end{tabular}

lower indicates a good fit $[31,32]$. For RMSEA a value less than 0.08 [33] explains a reasonable model fit, and more strictly values less than 0.06 shows a good model fit [32]. Considering incremental fit indices, it is generally suggested that a value close to 0.90 or above indicates a good model fit [30]. As the CFA's results showed, most of the indices had satisfactory values and they confirmed that the seven-factor structure of the ESSQ had a reasonable model fit with the sample data.

In order to improve the goodness fit of the model, a further investigation was conducted to modify the model. "The modifications are justified on the basis of assumed covariations between the errors of variances produced by the influences of social desirability and semantic similarity" [33]. The results of examining the modification indices suggested high error covariance between the following four pairs of items: es7_27 (I am aware of the ethical issues I face at school) and es7_28 (I am better than other people in recognizing new and current ethical problems); es5_17 (I recognize my own bias when I take a stand on ethical issues) and es5_18 (I realize that I am tied to certain prejudices when I assess ethical issues); es3_9 (I am able to cooperate with people who do not share my opinions on what is right and what is wrong) and es3_10 (I tolerate different ethical views in my surroundings); es6_23 (I am able to create many alternative ways to act when I face ethical problems in my life) and es7_28. Accordingly, these four cases which had the highest error covariance between items were left out from the model. When these errors were freed, the results showed a significant improvement in the values of all fit indices $\left(\chi^{2}=1055.52\right.$ $[\mathrm{df}=325 ; P<0.00]$, SRMR $=0.06$, RMSEA $=0.06$ with a $90 \%$ confidence interval of 0.059 and $0.068, \mathrm{CFI}=0.88$, GFI $=0.94$, IFI $=0.94$, NFI $=0.92$ ). This modification resulted in a good model fit of the sample data with regard to the seven dimensions of the ESSQ suggested in the original study [3].

5.1. Reliabilities of the ESSQ Scores. Using Cronbach's Alpha coefficient the reliability of the ESSQ was examined. The results showed that the overall reliability of the questionnaire was sufficiently high $(\alpha=0.84)$. Researchers suggest that the overall reliability of the test score should be 0.80 or higher [30]. From this, we can conclude that the test ESSQ had a high internal consistency with this sample. In addition, the reliability of each of the seven dimensions is presented in Table 2; the dimensions 5 (Preventing social bias) and 1
(Reading and expressing emotions) resulted in the lowest reliabilities (with $\alpha=0.45 ; \alpha=0.46$, resp.) Further inspection, with an inter-item covariance of both dimensions was made. The results suggested that, the item 5_18 (I realize that I am tied to certain prejudices when I assess ethical issues) and the item 1_3 (I notice if someone working with me is offended by me) had the highest covariance with other items in the mentioned dimensions. If we remove them, the reliabilities will increase to: $\alpha=0.49$ and $\alpha=0.50$ for dimensions 5 and 1 , respectively.

In general, the reliability of the ESSQ is good. The low reliability scores in two dimensions might be due to cultural differences in the sample of our study (Iranian culture) with original sample (Finnish culture). Highly abstract concepts involving such as ethical and moral issues could be differently interpreted in various cultures.

5.2. The Descriptions of Ethical Sensitivity in the Sample. In this part of presentation of our results, we will present the nature and level of ethical sensitivity in the target sample. The results showed that the level of ethical sensitivity in the sample was high $(M=3.85, \mathrm{SD}=0.36)$.

Considering the differences in the dimensions of the scale with overall mean score of the ethical sensitivity, the results showed that except for "Identifying the consequences of actions and options", there were statistically significant differences between other dimensions with overall mean of the scale (as test value). Table 3 shows the results of other dimensions. As it is shown, "Taking the perspective of others" received the highest score $(M=4.38, \mathrm{SD}=0.53)$ and showed a large mean difference with the overall mean of the scale (Mean. $d=0.51)$. On the other side, "Reading and expressing emotions" had the lowest mean score $(M=3.26$, $\mathrm{SD}=0.59)$ and resulted in the largest mean difference with the overall mean of the scale (Mean. $d=-0.59$ ).

Considering the three subgroups of the sample, the results suggested that there were no statistically significant differences among primary, middle, and high school teachers in the six dimensions of the scale. As shown in Table 4, in all dimensions, the perceived ethical sensitivity of primary and middle teachers was higher than that of high school teachers. In the dimension "Identifying the consequences of actions and options", the difference was statistically significant; the primary teachers $(M=3.93, \mathrm{SD}=0.45)$ perceived their ethical sensitivity more highly than did the middle $(M=$ $3.91, \mathrm{SD}=0.51)$ and high school teachers $(M=3.79, \mathrm{SD}=$ 
TABLE 3: Mean differences of dimensions of ethical sensitivity with overall mean score of ethical sensitivity among Iranian Kurdish teachers $(N=556)$.

\begin{tabular}{|c|c|c|c|c|c|}
\hline Dimensions & Mean & $\mathrm{SD}$ & Mean. $d$ & $t$ & $P$ \\
\hline Reading and expressing emotions & 3.26 & 0.59 & -0.59 & -23.77 & 0.000 \\
\hline Caring by connecting to others & 3.67 & 0.61 & -0.17 & -6.57 & 0.000 \\
\hline Taking the perspectives of others & 4.38 & 0.53 & 0.51 & 22.96 & 0.000 \\
\hline Working with interpersonal and group differences & 4.00 & 0.58 & 0.18 & 7.56 & 0.000 \\
\hline Preventing social bias & 3.71 & 0.50 & -0.14 & -6.94 & 0.000 \\
\hline Generating interpretations and options & 4 & 0.58 & 0.16 & 6.53 & 0.000 \\
\hline Identifying the consequences of actions and options & 3.88 & 0.51 & 0.03 & 0.65 & 0.51 \\
\hline
\end{tabular}

Test value $=3.85$, significance level $(0.05)$.

TABLe 4: Mean differences of dimensions of ethical sensitivity based on level of school $(N=556)$.

\begin{tabular}{|c|c|c|c|c|}
\hline Dimensions & $M$ & SD & $F$ & $P$ \\
\hline \multicolumn{5}{|l|}{ Reading and expressing emotions } \\
\hline Primary teachers $(N=125)$ & 3.22 & 0.53 & & \\
\hline Middle teachers $(N=221)$ & 3.30 & 0.61 & 1.14 & 0.33 \\
\hline High school teachers $(N=210)$ & 3.20 & 0.60 & & \\
\hline \multicolumn{5}{|l|}{ Caring by connecting to others } \\
\hline Primary teachers & 3.69 & 0.58 & & \\
\hline Middle teachers & 3.72 & 0.62 & 0.71 & 0.54 \\
\hline High school teachers & 3.64 & 0.62 & & \\
\hline \multicolumn{5}{|l|}{ Taking the perspectives of others } \\
\hline Primary teachers & 4.45 & 0.48 & & \\
\hline Middle teachers & 4.39 & 0.56 & 1.46 & 0.23 \\
\hline High school teachers & 4.32 & 0.52 & & \\
\hline \multicolumn{5}{|c|}{ Working with interpersonal and group differences } \\
\hline Primary teachers & 4.04 & 0.58 & & \\
\hline Middle teachers & 4.06 & 0.55 & 0.27 & 0.84 \\
\hline High school teachers & 4.02 & 0.59 & & \\
\hline \multicolumn{5}{|l|}{ Preventing social bias } \\
\hline Primary teachers & 3.73 & 0.49 & & \\
\hline Middle teachers & 3.74 & 0.47 & 1.99 & 0.11 \\
\hline High school teachers & 3.66 & 0.51 & & \\
\hline \multicolumn{5}{|l|}{ Generating interpretations and options } \\
\hline Primary teachers & 4.03 & 0.56 & & \\
\hline Middle teachers & 4.02 & 0.59 & & \\
\hline High school teachers & 4.01 & 0.58 & & \\
\hline \multicolumn{5}{|c|}{ Identifying the consequences of actions and options } \\
\hline Primary teachers & 3.93 & 0.45 & & \\
\hline Middle teachers & 3.91 & 0.51 & 2.99 & 0.03 \\
\hline High school teachers & 3.79 & 0.43 & & \\
\hline \multicolumn{5}{|l|}{ The ethical sensitivity (overall score) } \\
\hline Primary teachers & 3.87 & 0.34 & & \\
\hline Middle teachers & 3.87 & 0.35 & 1.54 & 0.21 \\
\hline High school teachers & 3.82 & 0.37 & & \\
\hline
\end{tabular}

Significance level (0.05). 
TABle 5: Mean differences of ethical sensitivity dimensions based on gender $(N$ : female $=224$; male $=332)$.

\begin{tabular}{lccccrrr}
\hline \multirow{2}{*}{ Dimensions } & \multicolumn{2}{c}{ Mean } & \multicolumn{2}{c}{ SD } & \multirow{2}{*}{ Mean. $d$} & \multirow{2}{*}{$t$} \\
& Male & Female & Male & Female & & \\
\hline Reading and expressing emotions & 3.39 & 3.07 & 0.56 & 0.57 & 0.314 & 6.38 & 0.000 \\
Caring by connecting to others & 3.74 & 3.60 & 0.59 & 0.63 & 0.146 & 2.77 & 0.006 \\
Taking the perspectives of others & 4.43 & 4.33 & 0.54 & 0.51 & 0.10 & 2.17 & 0.03 \\
Working with interpersonal and group differences & 4.08 & 3.99 & 0.53 & 0.63 & 0.09 & 1.81 & 0.07 \\
Preventing social bias & 3.74 & 3.66 & 0.48 & 0.50 & 0.07 & 1.80 & 0.07 \\
Generating interpretations and options & 4.04 & 3.98 & 0.54 & 0.61 & 0.06 & 1.26 & 0.20 \\
Identifying the consequences of actions and options & 3.89 & 3.84 & 0.49 & 0.53 & 0.052 & 1.19 & 0.23 \\
\hline
\end{tabular}

Significance level (0.05).

0.43). The Hochberg's Post Hoc inspection, however, showed that the differences between high school with primary and middle schools were statistically significant, while the difference between middle and primary teachers was not statistically significant.

Looking at gender, the results showed that there was a statistically significant differences between male and female in three dimensions of ethical sensitivity: reading and expressing emotions $(M$ : female $=3.07$, male $=3.39$; SD: female $=0.57$, male $=0.56$ ), caring by connecting to others $(M$ : female $=3.60$, male $=3.7 ;$ SD: female $=0.63$, male $=$ $0.59)$, and taking the perspective of others $(M$ : female $=4.33$, male $=4.3$; SD: female $=0.51$, male $=0.54)$. The other four dimensions resulted in no statistically significant differences. The results for gender differences are presented in Table 5.

\section{Conclusion and Discussion}

The present research was conducted on the premise that there was a need for measuring ethical sensitivity in different cultures and professional contexts. In line with this need, the Ethical Sensitivity Scale Questionnaire (ESSQ) was administered to a sample of 556 Iranian Kurdish teachers in order to (1) examine its validity in a different culture and (2) describe the level of ethical sensitivity in the targeted population. The ESSQ was originally developed by Tirri and Nokelainen and is based on Narvaez's theory [12] of seven dimensions of ethical sensitivity $[3,13]$.

The results of an initial Confirmatory Factor Analysis (CFA) showed that the ESSQ reflected a reasonable model fit of these seven dimensions of ethical sensitivity. However, in order to improve the model's goodness of fit, we needed to do some changes based on suggested modification indices in the CFA. The modification indices were mainly related to high error covariance between four pairs of items (7_27 and 7_28; 5_17 and 5_18; 3_9 and 3_10; 6_23 and 6_28). These modification indices can be explained by their face and content similarities. In other words, these pairs of items are somehow similar and thus examine the same content. In this way, our study confirms the results of previous studies [3] that the ESSQ supports Narvaez's theory [12] of seven dimensions of ethical sensitivity. Like these studies, our results suggested that a systematic item reduction was needed in order to remove some items from the model, particularly items with a high error covariance. Therefore, when we freed the error covariance of the mentioned pairs of items, the model's goodness of fit significantly increased according to various indices. In addition to validity, the reliability analysis suggested that the overall reliability of the scale was good. Regarding the seven dimensions, "Generating interpretations and options" and "taking the perspectives of others" resulted in the highest scores. On the other side, "Preventing social bias" and "Reading and expressing emotions" had lowest reliability scores. Further inspection suggested that removing two items (es5_18 and es1_3) with a high covariance resulted in better reliability scores for these two dimensions. As a result of validity and reliability analyses, we believe that the ESSQ supports a good model fit for studying the seven dimensions of ethical sensitivity, provided that the items with a high error covariance are removed from the model.

Further descriptive analysis with the ESSQ suggested that the level of perceived ethical sensitivity in the sample was high $(M=3.88 ; \mathrm{SD}=0.36)$. Such a result supports the idea of "teaching as a moral activity", which has been reflected in several important studies [34-38]. In these studies, "caring" is considered to be a fundamental competency for teachers in their day-to-day activities. The main idea of the so-called caring teaching is to conduct ethical and pedagogical actions so as to enhance the welfare of the students. In this way, ethical sensitivity is an initial and very important step in conducting caring pedagogy. This is why the teachers selfreported ethical sensitivity was high in this study and the other study in Finish context [28].

More in-depth analysis showed that the highest and the lowest self-reported dimensions of ethical sensitivity among Iranian Kurdish teachers were "Taking the perspective of others" and "Reading and expressing emotions," respectively. These results can be explained by two important phenomena. First, Iranians and particularly Kurds are known to have a collective culture and mentality in which "taking care of the perspective of others" has a significant place. Second, to be concerned about "the other" is the main idea of ethical sensitivity. As such, on the one hand, "taking the perspective of others" may reflect a part of Kurdish collective culture in which commitment to people and others is highlighted and considered as an essential value. Our results supported the previous findings where collective values predicted higher "empathic concern and perspective 
taking" among Iranians [39]. According to Ghorbani et al., empathic concern and perspective taking presumably are central to maintaining an adaptive allocentric sensitivity to others [39]. On the other hand, "reading (and particularly) expressing emotions" somehow reflects "taking care" of "oneself" and thus may have caused less attention from Kurdish teachers. Other research shows that "assertiveness, autonomy, freedom, self-fulfillment, and a sense of personal uniqueness" are associated with individualist values in which commitment to reason is emphasized [39].

The last part of the descriptive results showed that the lower grade teachers generally perceived a high level of ethical sensitivity. However, it was only the dimension of "Identifying the consequences of actions and options" that resulted in statistically significant differences among primary, middle, and high school teachers. In general, primary and middle teachers reported higher ethical sensitivity than high school teachers, when it comes to identifying the consequences of their actions. This is due to the fact that the younger students are prone to more negative consequences as the result of careless activities on the part of their teachers. This part of our results opens up the idea that ethical sensitivity may be associated with different demographic and mediating variables. In various contexts, ethical sensitivity was found to be associated with age and the professional positions of the respondents [40], gender [41], culture [42] and giftedness [3]. As such, a further line of research will be to model the path structure of ethical sensitivity in different contexts, including teaching and teacher education.

Considering the main task of this paper, we suggest that the ESSQ is a promising tool for measuring the seven components of ethical sensitivity. However, a systematic item reduction and modification will be needed to increase the model fit of the scale. In this study, some modifications based on covariations between four pairs of items were suggested. It would be worth to reexamining the stability of the scale in line with this modification in other studies. In addition, we should point out that moral competency including ethical sensitivity deals with a lot of complex meaning and dimensions in different cultures. Thus, quantitative study and the instrument we used in this study may not fully cope with this complexity. In order to deal with this limitation, we suggest further qualitative study to gain more insights into teachers' moral competencies including ethical sensitivity in an Islamic context.

\section{References}

[1] J. R. Rest, "Morality," in Handbook of Child Psychology, Cognitive Development, P. H. Hussen, J. Flavell, and E. Monkmam, Eds., pp. 556-629, John Wiley \& Sons, New York, NY, USA, 1983.

[2] K. Weaver, J. Morse, and C. Mitcham, "Ethical sensitivity in professional practice: concept analysis," Journal of Advanced Nursing, vol. 62, no. 5, pp. 607-618, 2008.

[3] K. Tirri and P. Nokelainen, "Comparison of academically average and gifted students' self-rated ethical sensitivity," Educational Research and Evaluation, vol. 13, no. 6, pp. 587601, 2007.
[4] S. R. Sirin, M. M. Brabeck, A. Satiani, and L. Rogers-Serin, "Validation of a measure of ethical sensitivity and examination of the effects of previous multicultural and ethics courses on ethical sensitivity," Ethics and Behavior, vol. 13, no. 3, pp. 221235, 2003.

[5] E. C. Ameen, D. M. Guffey, and J. J. McMillan, "Gender differences in determining the ethical sensitivity of future accounting professionals," Journal of Business Ethics, vol. 15, no. 5, pp. 591-597, 1996.

[6] J. Jordan, "Taking the first step toward a moral action: a review of moral sensitivity measurement across domains," Journal of Genetic Psychology, vol. 168, no. 3, pp. 323-359, 2007.

[7] N. Ersoy and F. Göz, "The ethical sensitivity of nurses in Turkey," Nursing Ethics, vol. 8, no. 4, pp. 299-311, 2001.

[8] K. Lützén, A. Johansson, and G. Nordström, "Moral sensitivity: some differences between nurses and physicians," Nursing Ethics, vol. 7, no. 6, pp. 520-530, 2000.

[9] J. Schluter, S. Winch, and K. Holzhauser, "Nurses' moral sensitivity and hospital ethical climate: a literature review," Nursing Ethics, vol. 15, no. 3, pp. 305-321, 2008.

[10] S. R. Maier, "Do trade publications affect ethical sensitivity in newsrooms," Newspaper Research Journal, vol. 21, no. 1, pp. 41-50, 2000.

[11] S. Lysonski and W. Gaidis, "A cross-cultural comparison of the ethics of business students," Journal of Business Ethics, vol. 10, no. 2, pp. 141-150, 1991.

[12] D. Narvaez and L. G. Endicott, Ethical Sensitivity: Nurturing Character in the Classroom, EthEx Series Book 1, ACE Press, Notre Dame, Ind, USA, 2009.

[13] K. Tirri and P. Nokelainen, Measuring Multiple Intelligences and Moral Sensitivities in Education, Sense Publishers, Taipei, Taiwan, 2011.

[14] D. Narvaez, "Neurobiology, moral education and moral selfauthorship," in Moral Education and Development, D. J. de Ruyter and S. Miedema, Eds., pp. 31-43, Sense Publishers, 2011.

[15] A. Higgins, "Teaching as a moral activity: listening to teachers in Russia and the United States," Journal of Moral Education, vol. 24, no. 2, pp. 143-158, 1995.

[16] D. T. Hansen, "Teaching adn the moral life of classroom," Journal for Just and Caring Education, vol. 2, pp. 59-74, 1995.

[17] D. T. Hansen, "Reflections on the manner in teaching project," Journal of Curriculum Studies, vol. 33, no. 6, pp. 729-735, 2001.

[18] C. Fallona, "Manner in teaching: a study in observing and interpreting teachers' moral virtues," Teaching and Teacher Education, vol. 16, no. 7, pp. 681-695, 2000.

[19] G. D. Fenstermacher, "On the concept of manner and its visibility in teaching practice," Journal of Curriculum Studies, vol. 33, no. 6, pp. 639-653, 2001.

[20] V. Richardson and G. D. Fenstermacher, "Manner in teaching: the study in four parts," Journal of Curriculum Studies, vol. 33, no. 6, pp. 631-637, 2001.

[21] D. Narvaez, "Moral neuroeducation from early life through the lifespan," Neuroethics, vol. 5, no. 2, pp. 145-157, 2012.

[22] M. M. Brabeck, L. A. Rogers, S. Sirin et al., "Increasing ethical sensitivity to racial and gender intolerance in schools: development of the racial ethical sensitivity test," Ethics and Behavior, vol. 10, no. 2, pp. 119-137, 2000.

[23] K. K. Y. Cheng and A. B. Beigi, "Education and religion in Iran: the inclusiveness of EFL (English as a Foreign Language) textbooks," International Journal of Educational Development, vol. 32, no. 2, pp. 310-315, 2011.

[24] R. Samiei, "Teacher education in Iran and world (translation)," Teacher, vol. 7, no. 1, pp. 18-23, 2011. 
[25] A. Molaeinezhad and A. Zakavati, "Comparision of Teacher education curriculum in Iran, France, Malysia, Japan, and England (Translation)," Educational Innovation Quarterly, vol. 26, no. 7, pp. 35-62, 2008.

[26] T. Morita, "Islam, education and human rights in Iran," Human Rights Education in Asian Schools, pp. 77-79, 2003.

[27] D. Narvaez, "Integrative ethical education," in Handbook of Moral Development, pp. 703-733, Erlbaum, Mahwah, NJ, USA, 2006.

[28] E. Kuusisto, K. Tirri, and I. Rissanen, "Finnish teachers'ethical sensitivity," Education Research International. In press.

[29] K. Tirri, "Holistic school pedagogy and values: finnish teachers'and students' perspectives," International Jornal of Educational Research, vol. 50, no. 3, pp. 159-165, 2011.

[30] H. Hulpia, G. Devos, and Y. Rosseel, "Development and validation of scores on the distributed leadership inventory," Educational and Psychological Measurement, vol. 69, no. 6, pp. 1013-1034, 2009.

[31] L. T. Hu and P. M. Bentler, "Fit indices in covariance structural equation modeling: sensitivity to underparametrized model misspicication," Psychological Methods, vol. 3, no. 4, pp. 424453, 1998.

[32] L. T. Hu and P. M. Bentler, "Cutoff criteria for fit indexes in covariance structure analysis: conventional criteria versus new alternatives," Structural Equation Modeling, vol. 6, no. 1, pp. $1-55,1999$.

[33] J. Musek, "A general factor of personality: evidence for the Big One in the five-factor model," Journal of Research in Personality, vol. 41, no. 6, pp. 1213-1233, 2007.

[34] W. Carr, "The role of theory in the professional development of an educational theorist," Pedagogy, Culture \& Society, vol. 13, no. 3, pp. 333-346, 2005.

[35] J. Dunne, "An intricate fabric: understanding the rationality of practice," Pedagogy, Culture \& Society, vol. 13, no. 3, pp. 367390, 2005.

[36] J. Dunne, "Arguing for teaching as a practice: a reply to Alasdair macIntyre," Journal of Philosophy of Education, vol. 37, no. 2, pp. 353-369, 2003.

[37] K. Gholami, "Moral care and caring pedagogy: two dimensions of teachers' praxis," Pedagogy, Culture and Society, vol. 19, no. 1, pp. 133-151, 2011.

[38] S. Kemmis, "Knowing practice: searching for saliences," Pedagogy, Culture \& Society, vol. 13, no. 3, pp. 391-426, 2005.

[39] N. Ghorbani, M. N. Bing, P. J. Watson, H. K. Davison, and D. L. LeBreton, "Individualist and collectivist values: evidence of compatibility in Iran and the United States," Personality and Individual Differences, vol. 35, no. 2, pp. 431-447, 2003.

[40] N. Ersoy, "A study of the ethical sensitivity of physicians in Turkey," Nursing Ethics, vol. 10, no. 5, pp. 472-484, 2003.

[41] J. Tsalikis and M. Ortiz-Buonafina, "Ethical beliefs' differences of males and females," Journal of Business Ethics, vol. 9, no. 6, pp. 509-517, 1990.

[42] M. L. Roxas and J. Y. Stoneback, “The importance of gender across cultures in ethical decision-making," Journal of Business Ethics, vol. 50, no. 2, pp. 149-165, 2004. 


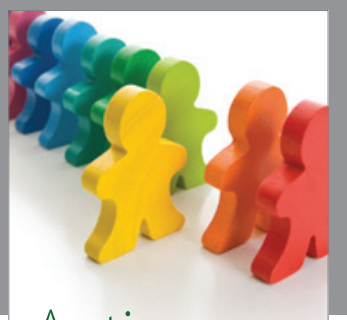

Autism

Research and Treatment
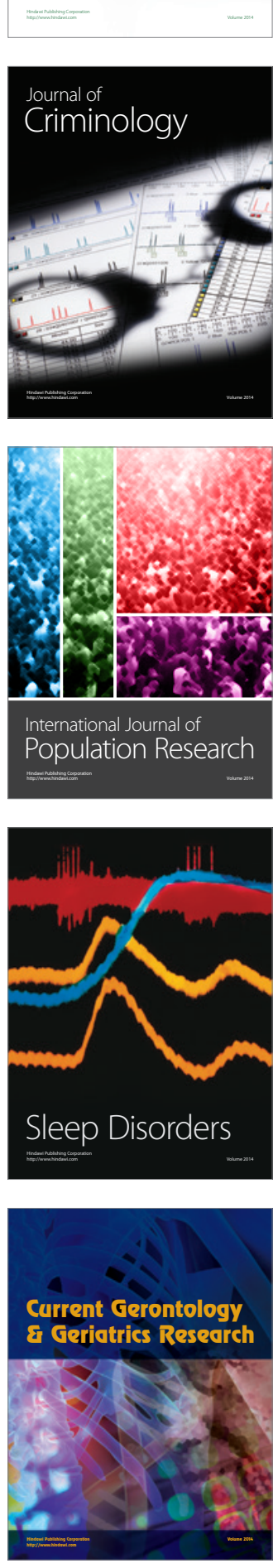
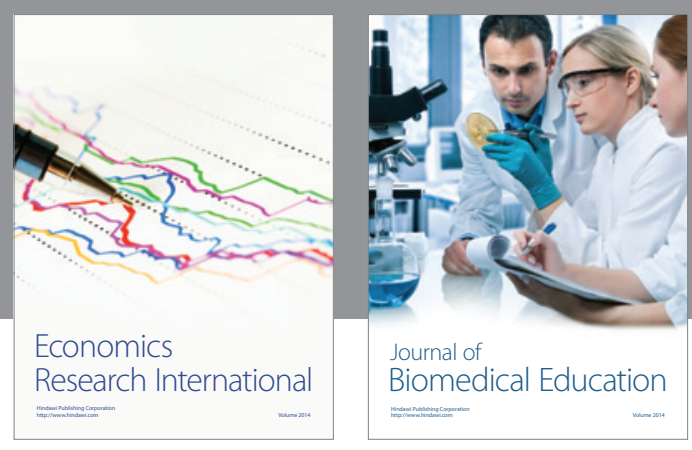

Journal of

Biomedical Education

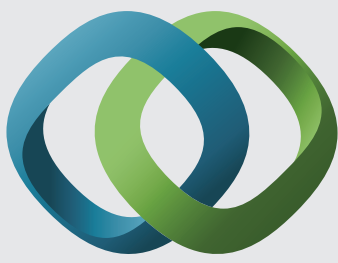

\section{Hindawi}

Submit your manuscripts at

http://www.hindawi.com
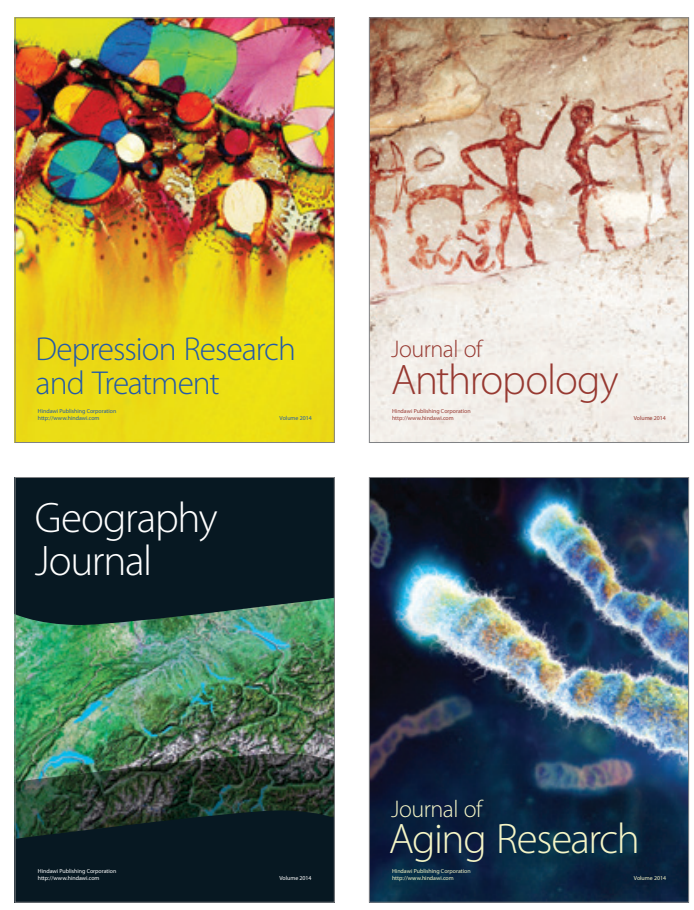

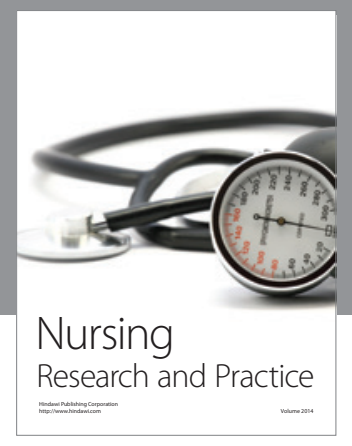

Nursing

Research and Practice

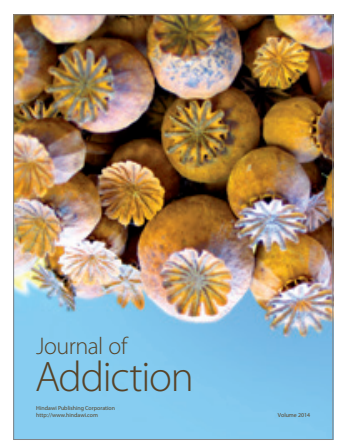

Child Development

Research

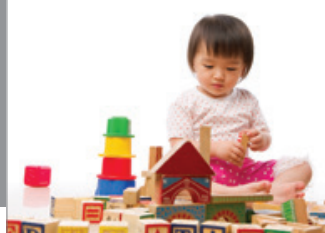

迥
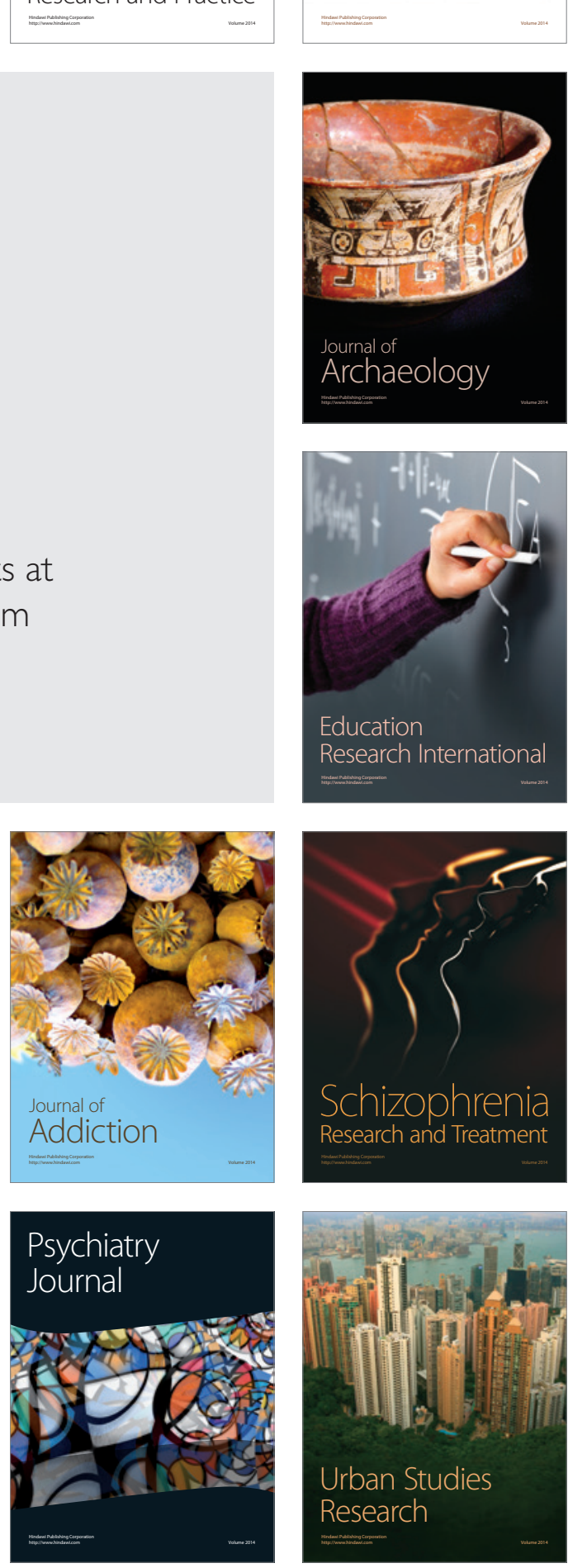